\title{
Efeito da sinvastatina em dose imunossupressora sobre as glândulas salivares e linfonodos cervicais de ratos Wistar
}

\section{Effects of simvastatin at immunosuppressive dose on salivary glands and cervical lymph nodes of Wistar rats}

Dayla Thyeme Higashi*

André Machado Xavier** Solange de Paula Ramos ${ }^{* * *}$

\section{Resumo}

Objetivo: avaliar a ação de dose imunossupressora da sinvastatina, droga utilizada para o controle da hipercolesterolemia, com efeitos pleiotrópicos anti-inflamatórios, imunomoduladores e antioxidantes, sobre a morfologia das glândulas salivares maiores e linfonodos cervicais de ratos Wistar. Materiais e método: foram utilizados 18 ratos Wistar machos divididos em dois grupos, o grupo controle (Co) $(n=6)$ receberam PBS estéril (i.p), os animais tratados (T7 e T21) $(n=12)$ receberam sinvastatina $(10 \mathrm{mg} / \mathrm{kg}$, i.p). Os animais foram sacrificados após 7 $(T 7, n=6)$ e 21 (T21, n=6) dias para avaliação da morfologia das glândulas parótida, submandibular, sublingual e linfonodos cervicais, além de análise de hemograma. Resultados: os grupos T7 e T21 apresentaram ácinos em menor quantidade e com menor área comparado ao grupo Co. Os linfonodos apresentaram menor número de centros germinativos por área no grupo T7; o grupo T21 não apresentou diferença em relação ao grupo Co. A análise hematológica demonstrou linfocitose e neutrofilia apenas aos 7 dias. Conclusão: a administração de sinvastatina em dose imunossupressora pode causar alterações tardias nas glândulas salivares e alterações transitórias nos linfonodos cervicais, podendo causar alteração da sua atividade funcional e protetora sobre as estruturas da cavidade oral.

Palavras-chave: Glândulas salivares. Linfonodos. Sinvastatina.

\section{Introdução}

A saliva é uma mistura complexa e tem um papel fundamental na manutenção da integridade e proteção dos tecidos bucais e vias aéreas superiores, preparação do bolo alimentar, deglutição e fala ${ }^{1}$. A secreção, em sua grande parte, é realizada pelas glândulas salivares maiores ${ }^{2}$, que são formadas por células acinares e ductos. Os ácinos da glândula parótida produzem mais fluido seroso rico em proteínas, as glândulas sublingual e submandibular tem produção de fluido mais rico em mucinas ${ }^{2}$ A produção salivar é controlada pelo sistema nervoso autônomo e muitos fármacos podem a alterá-la qualitativa e quantitativamente ${ }^{3}$, aumentando o risco de desenvolvimento de lesões bucais ${ }^{4,5}$. Um estudo em idosos sugere que as estatinas estão entre as medicações associadas à redução do fluxo salivar ${ }^{5}$.

Linfonodos cervicais fazem parte dos órgãos linfoides periféricos e participam da imunidade adaptativa, os antígenos são apresentados aos linfócitos pelas células apresentadoras de antígenos e proteínas do maior complexo de histocompatibilidade, iniciando assim a ativação de linfócitos e expansão clonal ${ }^{6}$.

As estatinas são inibidores da 3-hidroxi - 3-metilglutaril coenzima A reductase (HMG-CoA) uma

\footnotetext{
Mestranda em Odontologia (Clínica Odontológica) Universidade Estadual de Londrina (UEL) Departamento de Histologia Londrina - PR - Brasil.

Doutorando em Ciências Biológicas (Biologia Molecular) Universidade Federal de São Paulo (UNIFESP) Departamento de Biologia Molecular São Paulo - SP _ Brasil.

*** Professora Doutora Docente do Departamento de Histologia Universidade Estadual de Londrina (UEL) Departamento de Histologia Londrina - PR - Brasil.
} 
enzima que catalisa a produção do melavonato, o colesterol é um dos produtos desta via e a interrupção da mesma leva a queda dos níveis lipídicos, além disso, apresenta propriedades anti-inflamatórias e imunomoduladoras ${ }^{7}$. Estudos têm mostrado que a sinvastatina pode ser usada como agente imunomodulador da ação inflamatória, com potenciais implicações terapêuticas no tratamento de doenças inflamatórias crônicas ${ }^{8-11}$. A droga apresenta ação reduzindo o tônus simpático e aumentando a regulação parassimpática ${ }^{12,13}$, o que pode potencialmente interferir com a produção e secreção de saliva em pacientes durante o tratamento.

O objetivo deste trabalho é avaliar o efeito da sinvastatina, em dose imunossupressora, sobre a histomorfologia das glândulas salivares e linfonodos cervicais e discutir os efeitos que essas alterações podem ter sobre a manutenção da homeostasia da cavidade bucal e seus anexos.

\section{Materiais e método}

Todos os procedimentos abaixo descritos foram realizados em conformidade com os Princípios Éticos para Pesquisa Animal adotados pelo Colégio Brasileiro de Experimentação Animal (COBEA) [resolução 592 26/06/1992 do Conselho Federal de Medicina Veterinária e lei n. 9605 (regulada pelo Decreto n. 3179, 21/12/1999), e aprovado pelo Comitê de Ética em Experimentação Animal da Universidade Estadual de Londrina (protocolo CEEA 5/2010 37359). Foram utilizados dezoito ratos Wistar machos, $275 \pm 24 \mathrm{~g}$, obtidos do Biotério Central da Universidade Estadual de Londrina e mantidos no biotério de experimentação animal do departamento de Histologia/CCB/UEL. Os animais foram alojados em gaiolas plásticas, forradas com maravalha e alimentados com ração normocalórica (Nuvilab $^{\circledR}$ CR1, Nuvital Nutrientes, Colombo, PR, Brasil) e água potável à vontade. $\mathrm{O}$ ambiente foi mantido a aproximadamente $25^{\circ} \mathrm{C}$, em regime de luz/escuridão de 12 horas.

Os animais foram divididos em 2 grupos. O grupo controle (Co) $(n=06)$ recebeu 100 1 l de PBS estéril (i.p) durante 5 dias e, os grupos tratados $(n=12)$ receberam sinvastatina $(10 \mathrm{mg} / \mathrm{kg}$, i.p) durante 5 dias, e foram sacrificados no $7^{\mathrm{o}}$ dia $(\mathrm{T} 7, \mathrm{n}=06)$ e no $21^{\mathrm{o}}$ dia (T21, n=06) de experimentação. O sacrifício foi realizado com administração de dose letal de anestésico via intraperitoneal. A dose de 10/mg/kg de sinvastatina foi escolhida por apresentar ação imunomoduladora e anti-inflamatória em estudos com humanos ${ }^{10,11}$.

Para análise histológica as glândulas e os linfonodos do lado direito foram removidos, pesados e imediatamente fixados em solução fixadora de formalina tamponada $(\mathrm{Ph} / 7.2)$ durante 24 horas. A seguir, o material foi desidratado, diafanizado e embebido em parafina histológica. Cortes de $7 \mu \mathrm{m}$ foram submetidos a coloração de hematoxilina/eosina e analisados em microscopia de luz.

$\mathrm{Na}$ análise histomorfométrica das glândulas salivares, cinco imagens de cada glândula (totalizando 90 imagens de cada glândula) foram capturadas em 100X de aumento, por meio de sistema de captura de imagens Moticam (Motic, Xiamen, China). Posteriormente as imagens foram analisadas no software Motic Image Plus 2.0 (Motic, Xiamen, China). Foram avaliadas a área dos ácinos, a organização morfológica das células dos ácinos e ductos estriados, a preservação dos grânulos de secreção e a presença de infiltrado inflamatório ${ }^{14}$. Imagens capturadas em 40X de aumento dos linfonodos cervicais foram avaliadas quanto à área cortical, área paracortical e número de centros germinativos, conforme critérios adaptados de Elmore ${ }^{15}$ (2006), foram analisadas cinco imagens de cada linfonodo.

Sangue foi coletado por punção cardíaca em seringa contendo solução anti-coagulante (EDTA 5\%). A análise hematológica foi realizada em analisador hematológico automático (BC 2800 veterinary, Mindray Medical, Nanshan, China).

A comparação entre os grupos foi realizada por meio de teste paramétrico (teste $\mathrm{t}$ de Student) quando o teste Barlett não apresentou significância $(P>0.05)$, ou por estatística não paramétrica (teste de Mann-Whitney). As diferenças foram consideradas significativas quando $p<0.05$.

\section{Resultados}

O tratamento com sinvastatina não alterou o peso absoluto dos animais tratados em relação ao grupo controle aos sete dias. $\mathrm{O}$ peso relativo da glândula parótida também não apresentou diferença significativa representando cerca de $0,02 \%$ do peso absoluto dos ratos em ambos os grupos (Tababela 1).

Tabela 1 - Peso absoluto dos animais antes do sacrifício no grupo Co, T7 e T21. Não houve diferença significativa no peso entre o grupo Co e T7. O peso relativo da glândula parótida se manteve estável em todos os grupos experimentais

\begin{tabular}{l|c|c|c}
\cline { 2 - 4 } & Co & T7 & T21 \\
\hline $\begin{array}{l}\text { Peso total do animal (g) } \\
\text { Peso da glândula }\end{array}$ & $220,4 \pm 7,6 \mathrm{~g}$ & $194,4 \pm 3,6 \mathrm{~g}$ & $325.1 \pm 8.2 \mathrm{~g}$ \\
parótida (g) & $0.49 \pm 0.04$ & $0.50 \pm 0.03$ & $0.49 \pm 0.06$ \\
$\begin{array}{l}\text { Peso relativo da } \\
\text { glândula parótida }(\%)\end{array}$ & $0.02 \pm 0.002$ & $0.02 \pm 0.001$ & $0.02 \pm 0.001$ \\
\hline
\end{tabular}

As glândulas salivares foram avaliadas quanto ao número de ácinos por área $\left(9.10^{5} \mathrm{um}^{2}\right)$. Foi observado um número reduzido de ácinos nas glândulas sublingual, submandibular e parótida no $7^{\circ}$ e $21^{\circ}$ dias, em relação ao grupo controle (Figura 1). Os valores apresentaram significância apenas referente à glândula submandibular. 

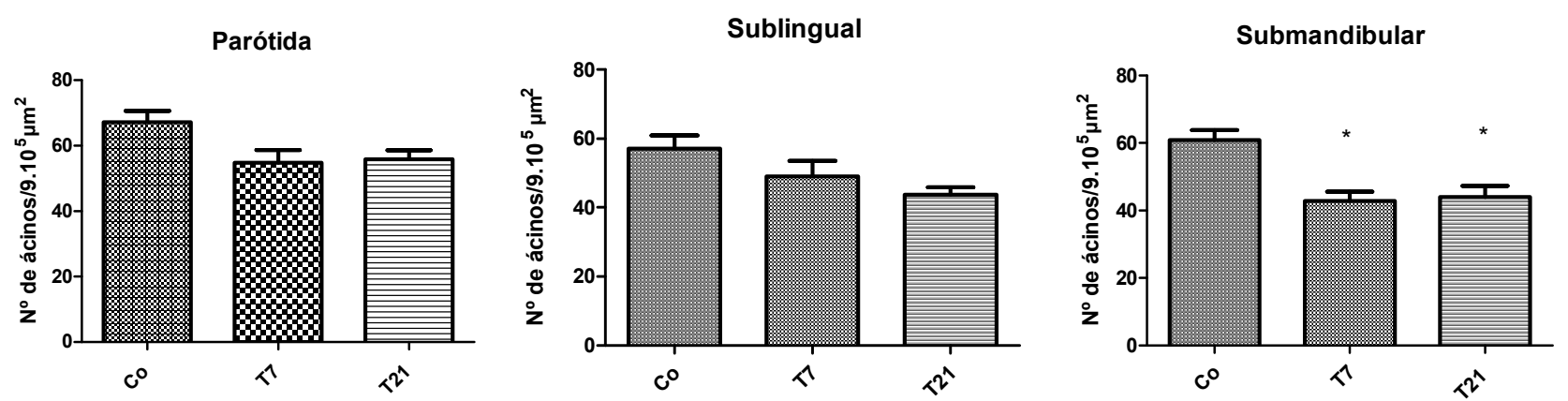

Figura 1 - Número médio $( \pm S D)$ de ácinos por áreas $\left(9.10^{5} \mu m^{2}\right)$ de parênquima glandular em parótida, submandibular e sublingual. Teste ANOVA e teste post hoc de Tukey. ${ }^{*} \mathrm{P} 0,5$.

A área média dos ácinos da glândula parótida foi significativamente maior nos animais do grupo T21 em relação aos grupos Co e T7. A área média dos ácinos das glândulas submandibular e sublingual foi maior aos 7 e 21 dias, em relação ao grupo controle ${ }^{* *} \mathrm{P}<0,05 \mathrm{e}^{* * * *} \mathrm{P}<0,005$ (Figura 2 ).
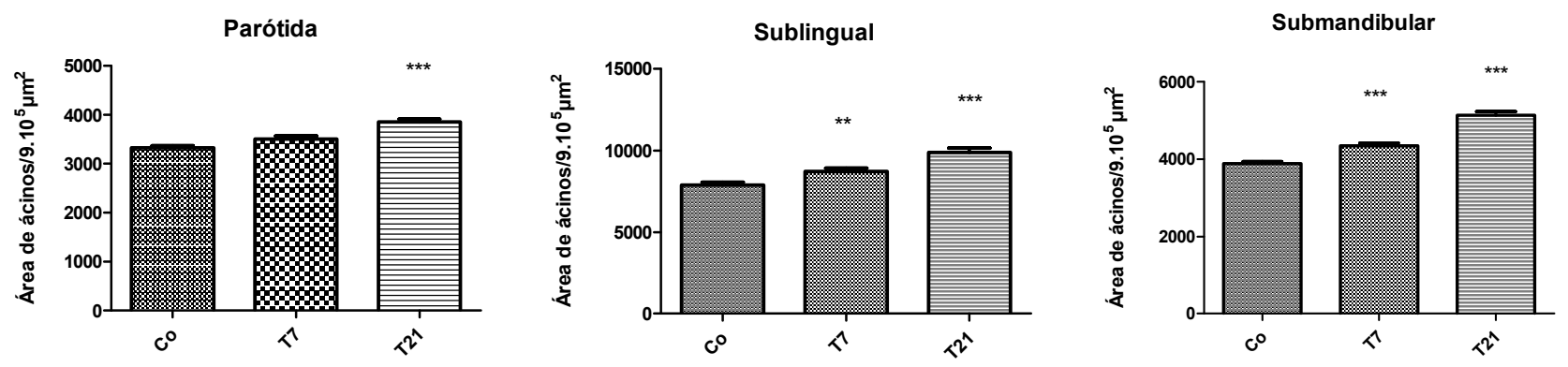

Figura 2 - Área obtida de ácinos presentes por campo analisado (9.105 $\mu \mathrm{m} 2)$ em parênquima glandular de parótida, submandibular e sublingual. Teste ANOVA e teste post hoc de Tukey. ${ }^{* * P}<0,05$ e ${ }^{* * *} P<0,005$

Não foi observada alteração nos ductos intercalares e estriados. O estroma glandular mostra cápsula e septos intactos, sem presença de infiltrado inflamatório e fibrose.

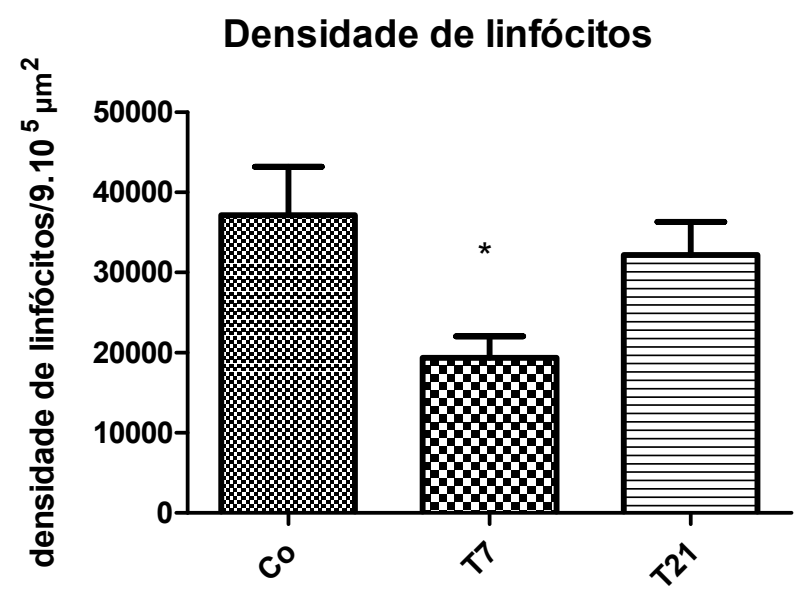

Os linfonodos cervicais apresentaram acentuada diminuição da densidade de linfócitos, principalmente no córtex e paracórtex no grupo T7 (Figura 3). Não foi observada redução significante do número de centros germinativos em T7 e T21 (Figura 3).

Figura 3 - Número de centros germinativos por campo analisado (9.10 $\mu^{2} \mathrm{~m}^{2}$ em linfonodo cervical. Teste ANOVA e teste post hoc de Tukey.

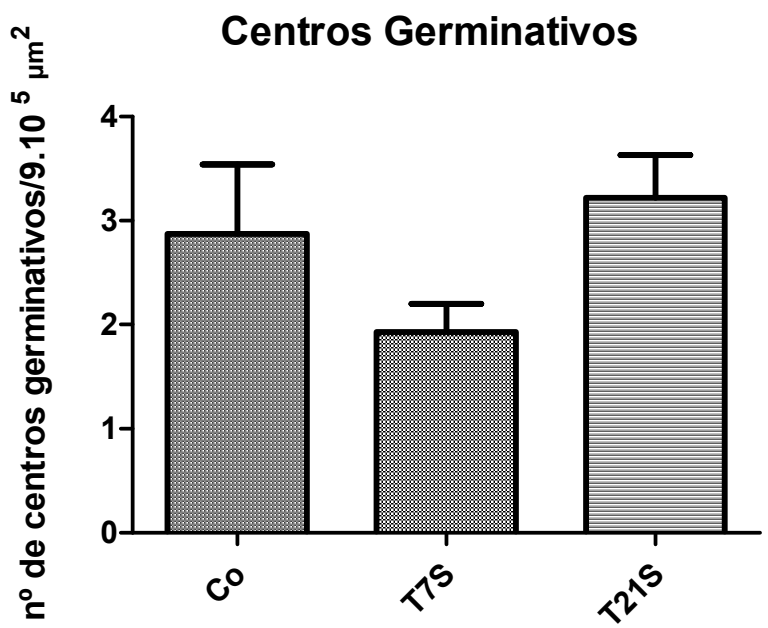

\footnotetext{
*PO,5.
} 
A análise hematológica aos sete dias de tratamento revelou leucocitose, linfocitose e neutrofilia. Aos vinte e um dias a análise hematológica não demonstrou diferenças em relação ao grupo controle (Tabela 2).

Tabela 2 - Análise hematológica. No $7^{o}$ dia observou-se leucocitose, linfocitose e neutrofilia $\left({ }^{*} P 0,5 ;{ }^{* *} P<0,05\right)$

\begin{tabular}{l|c|c|c}
\cline { 2 - 3 } & Co & T7 & T21 \\
\hline Leucócitos & $11517 \pm 1305$ & $26140 \pm 6090\left(^{* *}\right)$ & $17040 \pm 2608$ \\
Hemoglobina & $14,49 \pm 0,8$ & $14,38 \pm 1,2$ & $14 \pm 0,7$ \\
Hemácias & $7,13 \pm 0.06$ & $7,12 \pm 0.49$ & $7,59 \pm 0.68$ \\
Hematócrito & $43,33 \pm 0,57$ & $43,4 \pm 3,57$ & $40,42 \pm 1,65$ \\
Segmentado & $3122 \pm 529,5$ & $11880 \pm 4465,4\left(^{*}\right)$ & $344,8 \pm 6612,4$ \\
Linfócitos & $7995 \pm 618,3$ & $14210 \pm 2772(* *)$ & $7207 \pm 1320$ \\
\hline
\end{tabular}

\section{Discussão}

Com base nos resultados observaram-se alterações morfológicas nas três glândulas salivares dos animais tratados com dose imunossupressora de sinvastatina. A ação protetora da saliva tem sido utilizada como fonte de investigação não invasiva do metabolismo e eliminação de muitas drogas, além de funcionar como um marcador imunitário sistêmico, de acordo com a variação da quantidade de IgA secretora. Porém esta somente recebe atenção e tratamento quando apresenta alterações em quantidade ou qualidade no fluxo que passam a incomodar os pacientes ${ }^{16-18}$.

O ritmo de secreção das glândulas maiores é descontínuo, portanto depende do estado funcional em que se encontram. Em repouso, apresenta muitos grânulos de secreção, porém se em atividade apresentará menos grânulos. A morfologia dos ácinos pode também indicar o estado de hiper ou hipoativação associado ao efeito de drogas e algumas doenças ${ }^{1,19}$. A modulação da secreção salivar é restrita ao sistema nervoso autônomo, as vias parassimpáticas eferentes para as glândulas sublingual e submandibular originam-se do nervo facial por meio do gânglio submandibular e a glândula parótida recebe inervação do nervo glossofaríngeo pelo no nervo ótico ${ }^{19,20}$. Essas vias regulam a secreção líquida da saliva pela liberação da acetilcolina (Ach) na superfície das células acinares da glândula salivar, a secreção das macromoléculas está regulada pela noradrenalina, liberadas pelos nervos simpáticos (2). Portanto, as glândulas salivares podem estabelecer sensibilidade a agentes farmacológicos autonômicos ${ }^{19,21}$.

As estatinas são drogas inibidoras da HGM-CoA que são usadas para controle do colesterol, porém sabe-se que essas drogas têm muitos efeitos pleiotrópicos, incluindo a regulação da atividade do sis- tema nervoso autonômico e do sistema imune. As estatinas restauram a função autonômica do sistema cardiovascular na insuficiência cardíaca congestiva $^{22}$ e modulam sua ação em casos de arritmias ventriculares e atriais pela diminuição da atividade nervosa simpática ${ }^{23-25}$. Outros estudos mostram sua ação no fluxo simpático por interferência na síntese de óxido nítrico ${ }^{23}$, isso é possível pela diminuição da prenilação de Rho-quinase ${ }^{22,26}$. A influência sobre o sistema autônomo também foi observada em células da medula adrenal bovina, a administração de sinvastatina induziu à síntese de acetilcolina por meio da supressão do fluxo de $\mathrm{Na}+\mathrm{e} \mathrm{Ca} 2+{ }^{25}$.

A estimulação parassimpática aumenta consideravelmente o volume de secreção salivar, isso deve-se quase que totalmente à formação da guanosina $3^{\prime} 5^{\prime}$ monofosfato cíclico que ocorre nos ácinos ${ }^{27}$. A elevada quantidade de guanosina $3^{\prime} 5^{\prime}$ monofosfato cíclico, que é um mensageiro, leva ao aumento dos ácinos, da atividade iônica e do mecanismo de transporte ativo, o que promove aumento de secreção pelas glândulas ${ }^{27-30}$.

No presente estudo observamos que as glândulas após a administração da droga apresentaram-se maiores e em menor número por campo, este resultado foi mais acentuado no grupo T21S. Este aumento de área dos ácinos nos sugere que estejam hipertrofiados, em função do aumento do sinal parassimpático. Como já foi dito a sinvastatina interfere com o sistema autonômico, deprimindo o sistema simpático, a modulação negativa do sistema simpático favorece a expressão do sistema parassimpático, o que pode levar as glândulas a um aumento da produção dos componentes líquidos e iônicos da saliva. Outros estudos com drogas que causam interferência no sistema autonômico também encontraram influências nas glândulas salivares ${ }^{1,21,31}$.

Nos órgãos linfoides secundários os antígenos são apresentados aos linfócitos pelas células apresentadoras de antígenos em conjunto com proteínas 
de classe II do complexo de maior histocompatibilidade (MHC) que chegam pela corrente sanguínea. O reconhecimento, ativação e expansão clonal pelos linfócitos é essencial para uma resposta imune adaptativa eficaz ${ }^{32}$. Sabe-se que a sinvastatina age sobre o sistema imunológico inato e adquirido, regulando a ativação de neutrófilos, macrófagos, da resposta imune celular (Th1), humoral (Th2), diminuindo a migração de células $\mathrm{T}$ e $\mathrm{B}$ para os órgãos linfóides secundários (baço, linfonodos) e de leucócitos para o sangue periférico, e a apresentação de antígenos via MHC de classe I e II ${ }^{6,33-37}$.

A migração dos linfócitos para os locais de infecção e órgãos linfoides secundários é governada pela adesão de moléculas, uma delas é a LFA-1 (antígeno 1 associado a função do linfócito), esta quando associada ao ligante ICAM-1 aumenta a adesão dos linfócitos a paredes dos vasos ${ }^{6}$. A sinvastatina aumenta a quantidade de LFA-1 e, consequentemente, aumenta a adesão dos linfócitos à parede das vênulas pós-capilates impedindo a migração desses ${ }^{6-33}$.

A avaliação histológica mostrou diminuição do número de centros germinativos por área analisada, o que comprova a ação da sinvastatina sobre os linfonodos, essa diferença foi maior no grupo T7, a ação imunossupressora da droga durou o período de sua administração. Também verificamos diminuição da contagem de linfócitos, Schramm et al. ${ }^{6}$ (2007) observaram que dose consideravelmente alta de estatinas reduz a celularidade de linfonodos cervicais em camundongos.

No grupo T21 o aspecto é muito semelhante ao do grupo controle, a sinvastatina é facilmente metabolizada e excretada, e no caso dos linfonodos não houve alterações morfológicas tardias decorrentes da administração da droga.

A análise hematológica aos sete dias de tratamento revelou leucocitose, linfocitose e neutrofilia. Aos vinte e um dias, a análise hematológica não demonstrou diferenças em relação ao grupo controle. Embora a análise do hemograma não tenha demonstrado alteração do número de linfócitos, a presença de neutrofilia pode indicar a retenção prolongada destas células na circulação, em função da diminuição da migração de leucócitos para os tecidos ${ }^{21}$.

Os anticorpos IgAs liberados na saliva são produzidos principalmente pelos linfonodos cervicais. Drogas imunossupressoras que promovam alterações no recrutamento e ativação dos linfócitos $\mathrm{T}$ e B nestes órgãos, podem potencialmente reduzir a quantidade de imunoglobulinas na saliva e aumentar o risco de infecções da cavidade bucal e vias aéreas superiores.

\section{Conclusão}

Conclui-se que a sinvastatina em dose imunossupressora pode provocar alterações tardias nas glândulas salivares, aumentando a densidade dos ácinos por área em função de uma possível modulação do tônus simpáticoe causa, também, alteração transitória nos linfonodos cervicais, diminunido o número de centros germinativos e induz leucocitose. É necessária a atenção imediata do cirurgião-dentista durante o período de administração da droga, pois as alterações nos linfonodos locais e parâmetros hematológicos podem predispor os indivíduos a infecções da cavidade bucal.

\section{Abstract}

Objective: to assess the effects of simvastatin, which is a drug used for the control of hypercholesterolemia and presents anti-inflammatory, immunomodulatory, and anti-oxidants effects, on the morphology of major salivary glands and cervical lymph nodes of Wistar rats. Materials and method: eighteenth male Wistar rats were divided into two groups: control group $(\mathrm{Co})(n=6)$ received sterile PBS (ip), treated group (T7 and T21) ( $n=12)$ received simvastatin $(10 \mathrm{mg} / \mathrm{kg}$, ip). The animals were sacrificed after $7(T 7, n=6)$ and $21(T 21 n=6)$ days to assess the morphology of the parotid, submandibular, and sublingual glands and cervical lymph nodes, in addition to CBC analysis. Results: T7 and T21 groups showed fewer and smaller acini, compared to Co group. Lymph nodes presented lower number of germinal centers per area for group T7, group T21 showed no differences compared to group Co. Hematological analysis showed lymphocytosis and neutrophilia only after 7 days. Conclusion: the administration of simvastatin at immunosuppressive doses may cause late changes in salivary glands and transient changes in cervical lymph nodes, which may alter its functional and protective activity on the structures of the oral cavity.

Keywords: Salivary glands. Lymph nodes. Simvastatin.

\section{Referências}

1. Wolff A, Zuk-Paz L, Kaplan I. Major salivary gland output differs between users and non-users of specific medication categories. Gerodontology [Comparative Study]. 2008;25(4):210-6.

2. Llena-Puy C. The role of saliva in maintaining oral health and as an aid to diagnosis. Med Oral Patol Oral Cir Bucal 2006;11(5):e449-55.

3. Samyn N, Laloup M, De Boeck G. Bioanalytical procedures for determination of drugs of abuse in oral fluid. Anal Bioanal Chem 2007;388(7):1437-53.

4. Hsieh SG, Hibbert S, Shaw P, Ahern V, Arora M. Association of cyclophosphamide use with dental developmental defects and salivary gland dysfunction in recipients of childhood antineoplastic therapy. Cancer 2011;117(10):2219-27.

5. Smidt D, Torpet LA, Nauntofte B, Heegaard KM, Pedersen AM. Associations between labial and whole salivary flow rates, systemic diseases and medications in a sample of older people. Com Dent Oral Epidemiol 2010;38(5):422-35.

6. Schramm R, Menger MD, Harder Y, Schmits R, Adam O, Weitz-Schmidt G, et al. Statins inhibit lymphocyte homing to peripheral lymph nodes. Immunology 2007;120(3):315-24. 
7. Ulivieri C, Fanigliulo D, Benati D, Pasini FL, Baldari CT. Simvastatin impairs humoral and cell-mediated immunity in mice by inhibiting lymphocyte homing, T-cell activation and antigen cross-presentation. Eur J Immunol 2008;38(10):2832-44.

8. Youssef S, Stuve O, Patarroyo JC, Ruiz PJ, Radosevich JL, Hur EM, et al. The HMG-CoA reductase inhibitor, atorvastatin, promotes a Th2 bias and reverses paralysis in central nervous system autoimmune disease. Nature 2002;420(6911):78-84.

9. Paraskevas KI. Statin treatment for rheumatoid arthritis: a promising novel indication. Clin Rheumatol 2008;27(3):281-7.

10. Maneechotesuwan K, Ekjiratrakul W, Kasetsinsombat K, Wongkajornsilp A, Barnes PJ. Statins enhance the anti-inflammatory effects of inhaled corticosteroids in asthmatic patients through increased induction of indoleamine 2, 3-dioxygenase. J Allergy Clin Immunol 2010;126(4):754-62.

11. Kirmizis D, Papagianni A, Dogrammatzi F, Skoura L, Belechri AM, Alexopoulos E, et al. Effects of simvastatin on markers of inflammation, oxidative stress and endothelial cell apoptosis in patients on chronic hemodialysis. J Atheroscler Thromb. 2010;17(12):1256-65.

12. Pliquett RU, Cornish KG, Peuler JD, Zucker IH. Simvastatin normalizes autonomic neural control in experimental heart failure. Circulation 2003;107(19):2493-8.

13. Tekin G, Tekin A, Canatar T, Sipahi I, Unsal A, Katircibasi $\mathrm{T}$, et al. Simvastatin improves the attenuated heart rate recovery of type 2 diabetics. Pharmacol Res 2006;54(6):442-6.

14. Medina VA, Prestifilippo JP, Croci M, Carabajal E, Bergoc RM, Elverdin JC, et al. Histamine prevents functional and morphological alterations of submandibular glands induced by ionising radiation. Int J Radiat Biol 2011;87(3):284-92.

15. Elmore SA. Enhanced histopathology of the lymph nodes. Toxicol Pathol 2006;34(5):634-47.

16. Humphrey SP, Williamson RT. A review of saliva: normal composition, flow, and function. J Prosthet Dent 2001;85(2):1629.

17. Tabak LA. A revolution in biomedical assessment: the development of salivary diagnostics. J Dent Educ 2001;65(12):13359

18. Almeida P del V de, Gregio AM, Machado MA, Lima AA de, Azevedo LR. Saliva composition and functions: a comprehensive review. J Contemp Dent Pract 2008;9(3):72-80.

19. Henderson KD, Andrew DJ. Regulation and function of Scr, exd, and hth in the Drosophila salivary gland. Dev Biol 2000;217(2):362-74.

20. Aps JK, Martens LC. Review: The physiology of saliva and transfer of drugs into saliva. Forensic Sci Int 2005;150(23):119-31.

21. Loy F, Diana M, Isola R, Solinas P, Isola M, Conti G, et al. Morphological evidence that pentagastrin regulates secretion in the human parotid gland. J Anat 2012;220(5):447-53.

22. Pliquett RU, Cornish KG, Zucker IH. Statin therapy restores sympathovagal balance in experimental heart failure. J Appl Physiol 2003;95(2):700-4.

23. Gao L, Wang W, Zucker IH. Simvastatin inhibits central sympathetic outflow in heart failure by a nitric-oxide synthase mechanism. J Pharmacol Exp Ther 2008;326(1):278-85.

24. Marin F, Pascual DA, Roldan V, Arribas JM, Ahumada M, Tornel PL, et al. Statins and postoperative risk of atrial fibrillation following coronary artery bypass grafting. Am J Cardiol 2006;97(1):55-60.

25. Matsuda T, Toyohira Y, Ueno S, Tsutsui M, Yanagihara N. Simvastatin inhibits catecholamine secretion and synthesis induced by acetylcholine via blocking $\mathrm{Na}+$ and $\mathrm{Ca} 2+$ influx in bovine adrenal medullary cells. J Pharmacol Exp Ther 2008;327(1):130-6.

26. Laufs U, Liao JK. Post-transcriptional regulation of endothelial nitric oxide synthase mRNA stability by Rho GTPase. J Biol Chem 1998;273(37):24266-71.

27. Dorman HL, Bellinger LL, Frazier LW, Williams FE. Salivary gland secretion. Physiologist 1981;24(5):51-3.

28. Melvin JE, Yule D, Shuttleworth T, Begenisich T. Regulation of fluid and electrolyte secretion in salivary gland acinar cells. Annu Rev Physiol 2005;67:445-69.

29. Prince WT, Berridge MJ, Rasmussen H. Role of calcium and adenosine-3':5'-cyclic monophosphate in controlling fly salivary gland secretion. Proc Natl Acad Sci U S A. 1972;69(3):553-7.

30. Rubin RP, Carchman RA, Jaanus SD. Role of calcium and adenosine cyclic 3'-5' phosphate in action of adrenocorticotropin. Nat New Biol 1972;240(100):150-2.

31. Godoy T, Riva A, Ekstrom J. Atypical antipsychotics--effects of amisulpride on salivary secretion and on clozapine-induced sialorrhea. Oral Dis 2012;18(7):680-91.

32. Wiedle G, Dunon D, Imhof BA. Current concepts in lymphocyte homing and recirculation. Crit Rev Clin Lab Sci 2001;38(1):1-31.

33. Ulivieri C, Fanigliulo D, Benati D, Pasini FL, Baldari CT. Simvastatin impairs humoral and cell-mediated immunity in mice by inhibiting lymphocyte homing, T-cell activation and antigen cross-presentation. Eur J Immunol 2008; 38(10):2832-44.

34. Wu JL, Matsui S, Zong ZP, Nishikawa K, Sun BG, Katsuda $\mathrm{S}$, et al. Amelioration of myocarditis by statin through inhibiting cross-talk between antigen presenting cells and lymphocytes in rats. J Mol Cell Cardiol 2008;44(6):1023-31.

35. Zhang X, Jin J, Peng X, Ramgolam VS, Markovic-Plese S. Simvastatin inhibits IL-17 secretion by targeting multiple IL-17-regulatory cytokines and by inhibiting the expression of IL-17 transcription factor RORC in CD4+ lymphocytes. J Immunol 2008;180(10):6988-96.

36. Kanda H, Yokota K, Kohno C, Sawada T, Sato K, Yamaguchi $\mathrm{M}$, et al. Effects of low-dosage simvastatin on rheumatoid arthritis through reduction of Th1/Th2 and CD4/CD8 ratios. Mod Rheumatol 2007;17(5):364-8.

37. Habib A, Shamseddeen I, Nasrallah MS, Antoun TA, Nemer G, Bertoglio J, et al. Modulation of COX-2 expression by statins in human monocytic cells. Faseb J 2007;21(8):1665-74.

\section{Endereço para correspondência:}

Solange de Paula Ramos

Departamento de Histologia, Universidade

Estadual de Londrina.

Rodovia Celso Garcia Cid PR 445 Km 380

86051-990 - Londrina, PR - Brasil

Telefone: (43) 3371-4327

E-mail: ramossolange@yahoo.com

Recebido: 16/11/2014. Aceito: 04/05/2015. 